\title{
The Japanese as library patrons
}

\author{
By Yoshi Hendricks
}

Head, Bibliographic Control

University of Nevada, Reno

\section{An intercultural perspective on information literacy.}

A

ctive recruiting of Japanese students by

American universities, both public and private, is a recent trend. American universities are looking for ways to increase enrollment and are recruiting students in Asia, and the Japanese have the money to respond to that invitation. Several American universities have established "branches" in Japan. In 1988, the University of Nevada, Reno, celebrated the grand opening of its branch in Tokyo. It was the first American state university to undertake such a venture.

University entrance is a serious goal of almost all Japanese youth (especially boys) and their families, and it is fraught with academic, financial, and psychological difficulties. American universities offer an adventurous alternative. A bachelor's degree from the United States, although not very valuable in the Japanese labor market, is better than none. Thus, Japanese branches of American universities have a good chance for considerable initial success.

Students are admitted to a branch in Japan after passing an entrance exam, which typically covers general educational background and proficiency in English, and after an interview to evaluate their motivation and goals. Those accepted generally undergo a year of intensive training in English. They are then sent to the United States to attend the home university or another institution affiliated for this purpose. Those who still score low on the TOEFL (Test of English as a Foreign Language) can be accommodated in ESL (English as a second language) programs now available on most American campuses, or be admitted conditionally to academic programs until they achieve the 500 points on the TOEFL test that are usually required for admission.
The University of Nevada, Reno, now has over 200 Japanese students. At the rate of some 100 new students each year, the university expects to see as many as 400 Japanese students on its campus by the fifth year. These students find themselves suddenly immersed in a culture quite different from their own, and equally strange are the problems faced by campus service personnel, including library staff.

The purpose of this paper is to examine the problems posed to the library by the influx of Japanese students, and the effectiveness of library public service to these students, by exploring some of the differences between the two societies that

\section{Fluency in English is far from a guarantee of cultural under- standing or good communication.}

result in misunderstandings-both perceived and unperceived. Most people, asked to name the number one problem in dealing with foreign students, would probably reply "language." Language is certainly the most apparent obstacle, but a larger problem is culture-i.e., a set of typical behaviors or standardized social characteristics of a particular group of people.

Communication is essential for the desired quality of service to be rendered. A foreign person who speaks good English-which most Japanese do not-may give an American the illusion that there is good communication when, in fact, communication is terrible because of cultural differences. Fluency in English is far from a guarantee of cultural understanding or good communication. 
In all communication, there are basic assump tions, outside of the topic at hand, that are culturebased. For example, if a person nods while listening, the speaker of English is likely to assume there is comprehension or agreement or both. If that is not the case, there is a breakdown in communication. This is only one example in speech behavior, and there are many culture-bound assumptions in all areas of behavior. This realization is the first step toward successful interaction between two people of different cultures.

To understand the Japanese at all, it is essential to realize the importance of conformity and uniformity in Japan. They are all-pervasive, in the family, at school, and at work, from birth to death. The Japanese proverb, "The nail that sticks out will

\section{... it is essential to realize the importance of conformity and uniformity in Japan.}

be pounded down," epitomizes this attitude. It is difficult for Americans to conceive of the ramifications of this attitude, for conformity and uniformity are diametrically opposed to American values. While we value originality and creativity, Japanese society by its nature discourages these qualities from early childhood. In American elementary schools, children learn to pursue topics or projects that interest them and report their results in class. They collect information in a library, get help from their parents, even call up specialists for information. They are expected to show initiative. In Japan, students do what they are assigned, and they are not assigned creative or imaginative tasks. Written exams determine their grades, which in turn actually determine their success in life: enter a better kindergarten for a better chance to enter a better elementary school for a better chance to enter a better middle school for a better chance to enter a better high school for a better chance to enter a good university for a better chance for employment with a better company and marriage to a "better" partner.

At school, the teacher may call on a student to read aloud or to answer a question, or may ask for a volunteer. Just like an American classroom, right? Wrong! In the American classroom, students are usually not afraid to speak. Some whose hands are up have the correct answer; others don't. In the Japanese classroom, many who know the correct answer don't raise their hands, and volunteers are few. Since grades are determined exclusively by test scores, why be a nail that sticks out?

The Japanese call their own culture a "society of shame." A list of what constitutes "shame" would be long indeed, but it certainly includes giving the wrong answer in class. The sociopsychological cost of making any kind of mistake in Japanese society is very high, regardless of the inherent importance of the error or its consequences.

Elementary, middle, and high schools are equipped with a "library room," which serves mainly as a study hall. A library clerk is in charge of the room. The teacher takes the class to the library room once during the school year for orientation. If a student uses the library services of the room after that, it would be only for ready reference in encyclopedias and dictionaries. Libraries do not play the role in Japan that they do in the United States. Japan is well known to have the highest literacy rate in the world, and everyone in Japan seems to be reading all the time. However, the Japanese are more likely to buy the books they want to read than to borrow them from a library. Book sales in Japan are enormous, and there is always a line at the checkstands of bookstores.

The bookstore scene in Japan is a novelty to Americans. From early evening to late night, customers stand in bookstores to read books and magazines that interest them. Some customers even leave a marker in a book for their next opportunity to come in and read it. Japanese bookstore managers, unlike Americans, don't seem to mind.

In Japan, there are few professional librarians as we know them. As in Europe, libraries have been managed by specially trained clerks or, in the case of academic libraries, by curators who might be historians. Keio University, a prestigious private school, opened its first program in library science in the $1960 \mathrm{~s}$, and other training centers have since appeared. The services expected by educated library users in the United States, such as reference service, are generally unknown in Japan. Libraries serve as a study hall for some and as a place for elementary students to borrow books for recreational reading. Occasionally, a patron uses a public library for demographic or other local research. One sees scholarly types sitting in the same spot in public libraries day after day with papers from their briefcases or books spread out in front of them.

There are libraries in Japanese universities, and specially trained staff performs computer searching and interlibrary mailing of scientific and technical articles from Japanese and international journals, especially in medicine, the natural and physical sciences, and engineering. The undergraduate student, however, rarely uses the library for research, since he is not required to do so.

The importance which the Japanese attach to admission to a university, preferably a prestigious one, is legendary. Years of cramming, including attending special prep schools late into the night, is necessary, and failure sometimes leads to suicide. College students, on the other hand, don't study! 


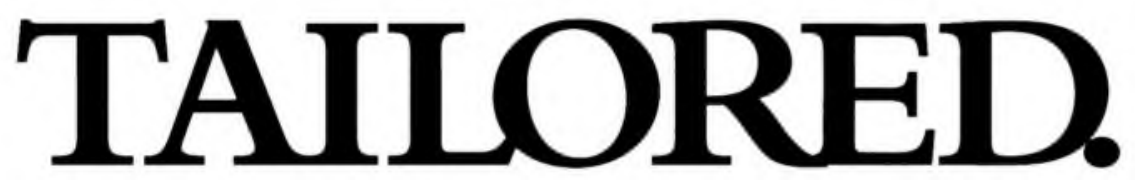

\section{Why Blackwell is the Approval Plan leader.}

\section{Academic and research libraries worldwide choose Blackwell for new \\ titles because we offer services tailored precisely to their needs.}

Service. You benefit because we are large enough to offer a full range of services, yet flexible enough to tailor those services to your needs.

Comprehensive coverage. Our buyers are in daily contact with the publishers whose books are so essential to your collection. These include not only university, trade and Sci-Tech-Med presses, but also the scholarly and small presses which you need for timely, full coverage. Our unique B. H. Blackwell interface offers 100\% coverage of UK new titles. Tailored profiling. Create your individualized library profile to select books of interest, based on our extensive subject thesaurus, our new LC classification thesaurus, or a combination of both. The choices are yours.

Computer access. Innovative new services such as our New Titles Online (NTO) and New Titles Announcement Service on diskette (PCNTAS) provide current, accurate book status information on your PC .

Tailored invoicing and reports. We arrange invoices to your specifications, and provide a complete package of management reports, including a projection of books and forms you will receive in the coming year and their estimated costs for budgeting.

Extensive, interactive database. Our approval, firm order and standing order systems interact to prevent duplication.

Unique backrun capabilities. What have you missed? We can show you the effect of expanding your plan, or tape match against your catalog.

\section{BLACKWELL \\ NORTH AMERICA, INC.}

Part of a proud bookselling tradition dating from 1879 .

Lake Oswego, Oregon • Blackwood, New Jersey

Toll free I-800-547-6426 
As Jared Taylor writes in Shadows of the Rising Sun: A Critical View of the Japanese Miracle (New York: Morrow, 1983), "For most Japanese, serious schoolwork ends in high school." Those who don't go to college are often heard to say, "I wish I could go to college to play."

It is with this background that the Japanese undergraduate arrives on the American campus. The student finds to his surprise that he is expected not only to study but to do library research in his humanities classes from the very beginning. His American classmates have been doing this since the sixth grade, at least.

\section{I sometimes encounter these}

students at the library entrance

as they are leaving the building after such a tour. It doesn't surprise me to hear (in Japanese, of course), "Did you understand anything?" "No, did you?" "I didn't, either."

First, he has to select a topic. Growing up and living in Japan do not train a person in making choices and decisions. All eventualities of life are considered, and the one correct solution to each is taught, for in Japan, there is only one correct way to do everything. Hundreds of titles designed to prepare the Japanese for having to make choices when abroad ("medium" for steak, "French" for dressing, etc.) are published in Japan.

Japanese students have written essays, but never a research paper from source material. They don't know about abstracts or indexes. Their only previous experience with reference books is with dictionaries and encyclopedias. Ask the teacher for help? Out of the question. Go to the reference desk? They never heard of it. They don't want to admit to anyone that they don't understand something. Maybe they can do the first assignment together with a trusted friend by trial and error, the blind leading the blind. I would be surprised if any undergraduate student from Japan had sought access to a library collection by using a card catalog or an online catalog.

Alphabetical listing is a formidable hurdle. We take alphabetical order for granted; it is so much a part of our society that it affects us long before we learn to read and write. We know alphabetical order without having to recite the alphabet each time. People whose native language doesn't employ the Roman alphabet don't.
Having to find something in the stacks is another obstacle. This is true even for native freshmen. Most academic and research libraries have several collections in the same building, which means that location symbols other than call numbers have to be understood. Large American libraries, therefore, are bewildering. College life would have been so much simpler and easier in Japan!

There is also the tremendous language barrier. Students from China speak amazingly good English, but those from Japan do not. After having taken English as a mandatory subject for at least six years, the Japanese can neither speak with any degree of fluency nor understand when spoken to. What is taught in Japanese schools is a stilted, really awkward English for the sole purpose of passing college entrance exams. Translating English text, perhaps Shakespeare, into Japanese and learning grammatical terms are the two main activities in English class, and test scores depend on these two skills. Often, even the teachers could not carry on a conversation in English. One reason is that language learning requires practice, which presupposes imperfection, but Japanese society does not allow for error. Since making a mistake is not $O K$, most Japanese people are very reluctant to speak a foreign language, especially in front of somebody!

In addition, the Japanese have speech behaviors that are puzzling to the English speaker. Nodding the head as part of their listening behavior, without implying either understanding or agreement, was mentioned above. Another peculiarity is that to the question, "Did you understand?" the Japanese person will insist, "Oh, yes"; but if you ask, "What did I say?" the answer will probably be: "I don't know." Another source of misunderstanding is that in Japanese as in Spanish, the negative response to a negatively phrased question is the reverse of English practice. In reply to the question, "You didn't bring any money either?" "Yes" would mean "Yes, I did not," whereas "No" would mean "No, I did." The answer addresses whether the question is true to fact.

The public services staff in the library has to take all these factors into consideration in order to be successful with these newcomers on campus. At the library of the University of Nevada, Reno, special orientation tours for Japanese students are given at the request of the Intensive English Department, and for other foreign-student groups at the request of the English Department's ESL classes. I sometimes encounter these students at the library entrance as they are leaving the building after such a tour. It doesn't surprise me to hear (in Japanese, of course), "Did you understand anything?" "No, did you?" "I didn't, either." While it is sad to think that the library staff's efforts have been mostly wasted on this group, it is not surprising. In addition to having a problem with the language, the 
new Japanese students cannot help but feel that the whole fuss over the library is pretty irrelevant to them, for they do not understand how they are going to need this information.

I have no perfect prescription for that first tour, but here are some suggestions. Be very selective in what to point out, simply because the students do not understand. Take the group to the dictionary section in the reference area and show them Kenkyusha's English-Japanese and Japanese-English dictionaries. Most libraries have these. Explain that these and all material in this section cannot be taken outside the library. For essays and projects, many of these students will be assigned or will select topics related to Japan, topics they have never thought about before coming abroad. Japanese students are not aware of Kodansha Encyclopedia of Japan, found in most academic libraries, or of any other reference material about Japan in English. Besides learning about such sources as Europa Yearbook and Statesman's Yearbook, they need to understand and become convinced that the library has more recent and more accurate statistical and other information than they can obtain by writing to their parents or friends in Japan, and that this information is available now instead of weeks from now.

It might perhaps spark their interest to show them the New York Times Index and The Times Index, then assist two of the students to look up the great Kanto earthquake of 1923 or the marriage of the present Emperor Heisei in 1967, the first marriage to a commoner in Japanese imperial history. Then you could take them to the microfilm to find these two events in greater detail, with photographs. Again, select two students to execute the searches. You will have to select them, since Japanese students are not likely to volunteer. Having selected them, protect them from the embarrassment of making a mistake by showing them what to do step-by-step.

If you have a manual checkout system and students have to fill out cards, have each one try one. It is futile to hold up a card and say, "Now, this space is for the call number," etc. They don't know what a call number is, and they don't understand the language you are speaking.

For the rest, tell them to bring their first assignment to the reference desk for help and direction. At that time, they will be more interested because they have no choice about that assignment. Nevertheless, asking for help will be difficult for them; for one thing, in order to ask a question, one has to know what it is that one wants to know. No one wants to ask a "dumb question," but especially not the Japanese. It is therefore especially important for public service staff to approach the Japanese student to see whether help is needed.
But then what if the reference person does not understand what the Japanese patron is asking? The Japanese student gets the message that his English is incomprehensible. Maybe it's an $\mathrm{l} / \mathrm{r}$ problem. What if the patron doesn't understand the librarian's answer? He will nod as the librarian speaks, say "Thank you very much," and leave, hoping that his ignorance will never be discovered.

To speak slowly when speaking to foreigners seems to be the general advice, but that's not easy to do, because each person has a speech rate that is measurable on the sound spectrograph and is the same no matter what language that person is speaking. What makes a foreign language sound so fast, even when it is not being spoken very fast, is that the words are nun together. In class, each word was learned separately, and in print, words remain separate. Therefore, when one is not understood, it helps to separate the key words. Unfortunately, with the Japanese patron it is especially difficult to know whether you have been understood.

Another common suggestion is to use easy or simple words. This is dangerous advice. Since English as a second language is leamed from textbooks followed by literature, everyday words used in the family, among friends, when shopping, and in other informal situations may never have been encountered by a foreign student, even after years of study-spent in translating such authors as Shakespeare, Bertrand Russell, and Somerset Maugham. It's the big words native speakers learn in school that foreign students most readily recognize. What gives them the most trouble, needless to say, are idioms, but the native speaker, unfortunately, is usually unaware of using idioms. The language is full of them. Most native speakers can speak only in the way they are used to speaking, so perhaps this is a moot point.

Although xenophobes will say, "Why should we go out of our way to help foreigners? They came to our country, so they should learn our language and our ways," efforts are made to accommodate nonEnglish speakers in a variety of service areas, both public and private. Multilingual signs are seen in airplanes and hotels, and driver's license testing is done in Spanish and, along the West Coast, also in Japanese. This is not so much a matter of beliefs as it is a practical necessity in order to reach a growing nonnative population in this country. In library service, we want to reach our patrons. When large numbers of Japanese students suddenly flood our campuses, it becomes necessary for campus service personnel, including library staff, to learn about the social history of this group in order to reach them and serve them successfully, to fulfill our own mission. 